\title{
Selenium in the thyroid: physiology and pathology
}

\author{
Carolina De Fusco \\ Immacolata Cristina Nettore \\ Annamaria Colao \\ Paolo Emidio Macchia
}

Department of Clinical Medicine and Surgery University of Naples "Federico II", Naples, Italy

\author{
Address for correspondence: \\ Paolo Emidio Macchia \\ Department of Clinical Medicine and Surgery \\ University of Naples "Federico II", Naples, Italy \\ Via S. Pansini, 5 \\ 80131 Naples, Italy \\ E-mail:pmacchia@unina.it
}

\section{Summary}

Selenium (Se) is a trace element that plays a critical role in several processes for human health. The thyroid is the organ with the highest Se content per gram of tissue; in thyroid follicular cells, Se acts as antioxidant by contrasting the production of the reactive oxygen species that are generated during thyroid hormones biosynthesis. In addition, Se is part of the active site of the deoidinases, the enzymes responsible for thyroid hormones activation and inactivation.

Herein, the effects of Se supplementation in patients with thyroid related disorders have been reviewed on the basis of the studies published on this issue.

KEY WORDS: thyroid, selenium, autoimmunity, antioxidant.

Introduction

Selenium (Se) (from the Greek word "Selene" meaning Moon) is an essential trace element, that was discovered in 1817 by the Swedish chemist Jons Jacob Berzelius (1). Two hundred years later, Se was recognized as a fundamental micronutrient that plays a critical role in several processes for human health (2-4): in 1957 Schwarz discovered that traces of Se can prevent liver necrosis in vitamin-E-deficient rats (5) and some years later, in 1973, Rothruck demonstrated the biological function of $\mathrm{Se}$ as a cofactor of glutathione peroxidase (GPX) (6).
Se is the most powerful antioxidant agent present in the human body (7), it acts as a growth factor, contributes to the regulation of thyroid hormone biosynthesis, it is a modulator of cardiovascular health, is important in the prevention of neurodegenerative diseases and cancer, and its optimal serum concentrations are required for a correct immune response and fertility $(8,9)$.

Se plays an important role in human physiology, and it is a basic element for many biological processes. Its most important function is likely to be as a fundamental component of the selenoproteins (4). Selenoproteins are a group of proteins, encoded by at least 25 human genes (10), presenting in their catalytic site in the amino acid selenocysteine (Se-Cys).

The functions of several of the selenoproteins are now known and approximately half of them have been shown to protect the cell against the action of reactive oxygen species (ROS) $(10,11)$. Selenocysteine-containing proteins influence several biological processes and exhibit a wide range of functions including free radical catabolism, immune response and carcinogenesis $(9,11)$.

A severe Se deficiency is associated with serious endemic diseases such as Kashin-Beck disease (an osteoarthropathy reported in north-east Asia and Tibet), Keshan disease (a cardiomyopathy encountered in some regions of China), but also mixed ematous cretinism as reported in some areas of central Zaire (12). $\mathrm{Se}$ is present in nature in both inorganic and organic forms (13). Most of the human Se intake originates from diet, but other sources of Se are the drinking water, the environmental pollution, and dietary supplementation. In particular, cereals, organ meats and seafood contains considerable levels of $\mathrm{Se}$ in forms of selenocysteine and selenomethionine (14).

Se status varies significantly across different populations and different ethnic groups (4), ranging from severe deficiency to toxic levels $(2,4)$. The quantity and the type of Se in foods are not constant all over the world (15) and the high variability in Se intake is determined not only by the different Se concentration in the soil (i.e., volcanic grounds have lower Se content), but also by other factors that influence the availability of Se to the food chain or the presence of ions that can complex with $\mathrm{Se}(2,4)$.

The optimal Se intake is still very debate (16) since it has been reported that if a low serum Se can contribute and worsen chronic diseases also Se excesses are associated with toxicity (17-21).

Currently, a definition of the optimal Se intake is based on its role in the modulation of anti-oxidase activity, and the optimal nutritional level are those necessary to maximize the activity of the glutathione peroxidase 1 (GPX1). The optimal intake should bring Se plasmatic 
concentration around $95 \mu \mathrm{g} / \mathrm{L}$. (range 89-114) $(2,16)$. This corresponds to an intake of 75 and $60 \mu \mathrm{g} /$ day for men and women, respectively $(3,16)$. In the US, selenium intake ranges from $60-220 \mu \mathrm{g} /$ day $(21,22)$. Se intake in Europe is lower than in the US, with large variability across different countries, ranging from adequate or marginally adequate intakes in Western and Central Europe (30-90 $\mu \mathrm{g} /$ day) to low or deficient intakes in Eastern European countries (7-30 $\mu \mathrm{g} /$ day) (22).

\section{Role of selenium in thyroid physiology}

The thyroid gland has the highest content of Se per mass unit (23) compared to all other endocrine organs and tissues $(4,10)$, and the understanding of the fundamental role of Se in the thyroid has been increased significantly during the past few years (10).

Several selenoproteins are expressed in thyroid follicular cells (24-26). Among these, two isoforms of iodothyronine 5'-deiodinase (type1 and type2, DIO1 and DIO2), which produce active thyroid hormone (4); the thioredoxin reductase type 1 (27); the selenoprotein $\mathrm{P}(27)$; and three isoforms of glutathione peroxidase, two of which (GPX1 and GPX4) protect thyroid follicular cells from hydrogen peroxide generated by thyroid peroxidase (4), and the third (GPX3) which is present into the lumen, where seems to modulate hydrogen peroxide levels (28).

It is well known that thyroid physiology is closely dependent from the oxidative changes (29): during thyroid hormone biosynthesis, $\mathrm{H}_{2} \mathrm{O}_{2}$ is constantly produced in a considerable amount, thus exposing the thyroid follicular cells to high concentrations of $\mathrm{H}_{2} \mathrm{O}_{2}$ and ROS (1). The peroxidative damage is decreased by the action of the selenoenzymes systems which may be involved in the regulation of hormone biosynthesis (30). Of note, the amount of $\mathrm{H}_{2} \mathrm{O}_{2}$ produced in thyrocytes is similar to the amount that can be produced in activated leukocytes (31), however, while an activated leukocyte's has a life of a few hours, adult human thyrocyte's life spans almost seven years (32). Such a long life requires a very efficient anti-oxidative response process against $\mathrm{H}_{2} \mathrm{O}_{2}$ excess and this protective system is represented by selenoproteins with GPX3 in first line $(31,33,34)$. Intra thyroidal Se concentrations are critical for GPXs activity and unbalances in this process as consequence of reduced Se concentrations can increase the oxidative stress and produce damages to the thyroid follicular cells. These damages can determine, to the very end, cell death and hypothyroidism.

\section{Selenium and autoimmune thyroiditis}

Chronic autoimmune Hashimoto's thyroiditis (HT) is the most common thyroid disorder and it is the main cause of acquired hypothyroidism in iodine-sufficient areas (23). All over the world it has a very high prevalence, affecting about $3 \%$ of the population (35). HT is characterized by the presence of auto-antibodies directed to the thyroid epitopes (thyroglobulin and thyroperoxidase), which are closely associated with thyroid dysfunction as consequence of a progressive thyroidal damage and lymphocytic inflammation (36).

HT etiology is still unknown but several aspects are involved in its pathogenesis including genetic predisposition, endogenous and environmental factors, including Se deficiency. A role of Se deficiency was hypothesized by the observation of an higher incidence of $\mathrm{HT}$ in areas with severe Se deficiency (37).

Several studies have investigated the possible therapeutic effects of Se administration in patients with HT (12). In 2002, Gartner et al. conducted a randomized, placebo-controlled, blinded trial on 70 female patients in Germany, an area with mild Se and iodine deficiency. The endpoint of the study was to investigate the effects of a short-term Se supplementation on the natural corse of HT. The patients, all under T4 treatment at substitutive doses, were split in two groups: 36 patients received $200 \mu \mathrm{g}$ of sodium selenite/day for 3 months, and 34 patients received placebo. In the supplemented patients, serum Se levels increased from 0,87 to $1,09 \mu \mathrm{M}$ and at the same time anti-TPO antibodies levels dropped by $37 \%(37)$.

The same author followed up some of patients for a further 6 months with a further decrease of TPO-Ab levels (38).

In 2003, Duntas et al. reported a $46 \%$ drop in thyroid antibodies levels after administration for three months of $200 \mu \mathrm{g} /$ day of selenomethionine, and a $55,5 \%$ drop of antibodies levels after 6 months of treatment (39). Similar results have been reported by Mazokopakis in 2007 with the administration for one year of $200 \mu \mathrm{g} /$ day of selenomethionine (40).

In 2006, Turker et al. compared the efficacy of $100 \mu \mathrm{g}$ and $200 \mu \mathrm{g}$ of selenomethionine supplementation, concluding that a better effect in maximize GPX activities and suppress autoimmune activity is obtained using the higher dose (41)

In contrast with the previous studies, Karanikas et al. found no significant reduction in anti-TPO antibodies after 3 months of Se supplementation with $200 \mu \mathrm{g} /$ day of sodium selenite in a series of Austrian patients with HT (42).

In 2009, Nacamulli's study focused mainly on the effect of a year-long course of Se supplementation in Italian patients with early-stage HT and a normal thyroid function or mild hypofunction not receiving substitutive L-T4 therapy. 46 patients were treated with $80 \mu \mathrm{g} /$ day of sodium selenite for 12 months, while 30 patients were given no treatment. TPO-Ab or Tg-Ab level decreased significantly (30\% and $19 \%$, respectively) after 12 months in the Se-treated group, but not in the control group (43). More recently, Krysiak and Okopien conducted a randomized clinical trial involving a group of 170 euthyroid women with recently diagnosed and previously untreated Hashimoto's thyroiditis and 41 matched healthy subjects. The primary endpoint was to evaluate the effects of L-T4, Selenomethionine, or their combination on several inflammatory markers (TNF-alpha, IL-1B, IL-6, MCP-1, IL-2, INF-G, and high sensitivity CRP). The study demonstrated that $\mathrm{L}-\mathrm{T} 4$ treatment reduces monocyte release of TNF- $\alpha$, IL-1 $\beta$, IL-6, and MCP-1, whereas 
selenomethionine inhibits lymphocyte release of IL-2, INF-G, TNF-alpha, and plasma CRP levels. The decrease in cytokines was even strongest when both drugs were administrated together (44).

In 2011, Balazs analyzed IFN- $\gamma$-induced HLA-DR expression in cultured human thyrocytes at various concentrations of sodium selenite. Se has a dose-dependent inhibitory effect on the expression of HLA-DR and this effect shows an inverse correlation with anti-oxidative capacity, suggesting that this can be one of the mechanisms associated with the efficacy of Se supplementation in HT (45).

Finally, very recently Anastasilakis et al. described 86 patients with HT and supplemented with $200 \mu \mathrm{g} /$ day of Se or placebo. No changes in TSH, FT4, FT3 and TPO$\mathrm{Ab}$ levels were detected in Se supplemented patients, while a significant drop in Anti-Tg level $(p=0,001)$ was observed after a 6 months treatment (46).

Results on efficacy of Se supplementation in HT are still not univocal, however it seems that Se may improve the inflammatory activity in patients with HT. Such effect is more evident in areas of mild Se deficiency, but whether this effect is specific for HT or may also be effective in other endocrine autoimmune diseases has yet to be investigated.

\section{Selenium and post-partum thyroiditis}

Pregnancy is a period characterized by profound alterations in the biochemical parameters of thyroid gland and thyroid gland, on the other hand, influences the pregnancy. Thyroid autoimmunity is associated with an increased risk of miscarriage, women with elevated TPO-Ab are prone to develop hypothyroxinemia during pregnancy and thyroid dysfunction after delivery (47-49).

Recurrent abortions have been associated with lower serum Se levels (50), and during the 3rd trimester of gestation plasma Se levels drop significantly, returning to baseline after delivery with a risk, for pregnant women of Se deficiency.

Negro et al. reported the effect of Se supplementation on postpartum thyroid status in TPO-Ab positive pregnant women (51). The results indicate that Se supplementation reduced the incidence of post-partum thyroiditis and permanent hypothyroidism, and treated patients showed a significant decrease in the titer of TPO-Ab in the postpartum period, suggesting that selenium administration is effective in prevention of postpartum thyroiditis (PPT). Nevertheless, no other studies so far reported similar results and study replications are required before confirming the efficacy of $\mathrm{Se}$ supplementation in prevention of PPT (52).

\section{Selenium and Graves' disease}

Graves' Disease (GD), similarly to HT, is organ-specific autoimmune-inflammatory disease with a complex pathogenesis. GD is characterized by lymphocytic infiltration of the thyroid gland with the production of antibodies that bind to the thyrotropin receptor, miming the TSH action (53). The hyperstimulation of the TSH receptor causes an increase of thyroid hormone biosynthesis with $\mathrm{H}_{2} \mathrm{O}_{2}$ overproduction. This increases ROS production and oxidative stress of the thyroid follicular cell (3). It is now a common view that $\mathrm{H}_{2} \mathrm{O}_{2}$ is implicated in the pathogenesis of GD with an imbalance of the antioxidant/oxidant status, as suggested by several authors $(3,54,55)$.

In this view, adequate serum Se levels are fundamental to contrast the inflammatory processes: low serum Se levels have been reported in patients with hyperthyroidism and Graves' disease (56) being associated with the hyperthyroidism, since the administration of antithyroid drugs can increase plasma Se $(34,57)$. The efficacy of Se supplementation in GD has been suggested by Vrca et al., that demonstrated that patients with GD receiving in addition to methimazole also a supplementation with and antioxidant mixture of Se, beta-carotene, and vitamins $\mathrm{C}$ and $\mathrm{E}$, led to euthyroidism faster than patients treated with methimazole alone (58).

\section{Selenium and Graves' ophthalmopathy}

Graves' orbitopathy (GO) is caused by inflammation in the orbital connective tissue leading to an enhanced adipogenesis and overproduction of glycosaminoglycans. This causes an increase in orbital volume and fibrosis of the extra ocular muscles (59). Oxidative stress is involved in the pathogenesis of GO (60) as suggested by the results of studies reporting the efficacy of antioxidant treatment in GO.

In 2000, Bouzas et al. demonstrated that 9 of 11 (82\%) patients treated with oral antioxidants showed an improvement of mild to moderately severe Graves' ophthalmopathy while improvement was observed only in 3 of $11(27 \%)$ patients in the untreated group $(P<.05)$ (61).

A recent study conducted by Marcocci et al. compared the effects on GO of Se administration compared to an anti-inflammatory agent, pentoxifylline, and placebo (62). The results demonstrated that Se treatment was associated with an improved quality of life, less eye involvement and slower progression of GO, compared to placebo and to pentoxifylline. In addition, Se supplementation is associated with less side effects. The study has two limitations: the authors did not measured the effects on plasma Se concentration of Se administration, and the study was conducted in areas of moderate Se deficiency, which may potentiate the effects of Se supplementation.

In addition, no confirmatory studies have been reported, and further trials are necessary to define Se supplementation in the treatment of mild and moderate GO (60).

\section{Conclusions}

In this review the role of the trace element Se was analyzed for its effects on thyroid metabolism and diseases.

Se supplementation seems to produce benefits in the management of autoimmune thyroid disorders (Tab. 1). 
Table 1 - Clinical studies using selenium supplementation in patients with autoimmune thyroid disorders.

\begin{tabular}{|c|c|c|c|c|c|c|}
\hline Disease & Country & Follow-up & $\begin{array}{l}\text { Study } \\
\text { Gruop }\end{array}$ & Se dose & Major outcome & Author \\
\hline \multirow{9}{*}{ HT } & Germany & 3 months & $\begin{array}{c}70 \\
\text { patients } \\
(\mathrm{F})\end{array}$ & $\begin{array}{l}200 \mu \mathrm{g} / \text { day } \\
\text { (Se selenite) }\end{array}$ & Drop in TPO-Ab (-63.3\%) & (37) \\
\hline & Germany & 6 months & $\begin{array}{c}47 \\
\text { patients } \\
(\mathrm{F})\end{array}$ & $\begin{array}{l}200 \mu \mathrm{g} / \text { day } \\
\text { (Se selenite) }\end{array}$ & $\begin{array}{l}\text { Major decrease in TPO-Ab in } \\
\text { patients continuing } \\
\text { supplementation }\end{array}$ & (38) \\
\hline & Greece & 6 months & $\begin{array}{c}65 \\
\text { patients } \\
(56 \mathrm{~F} / 9 \\
\mathrm{M})\end{array}$ & $\begin{array}{c}200 \mu \mathrm{g} / \mathrm{day} \\
(\mathrm{SeMe})\end{array}$ & $\begin{array}{l}\text { Drop in TPO-Ab } \\
\text { (-46\% at } 3 \text { months; } \\
-55,5 \% \text { at } 6 \text { months) }\end{array}$ & (39) \\
\hline & Turkey & 9 months & $\begin{array}{c}88 \\
\text { patients } \\
(\mathrm{F})\end{array}$ & $\begin{array}{c}100 \text { or } 200 \mu \mathrm{g} / \mathrm{day} \\
(\mathrm{SeMe})\end{array}$ & $\begin{array}{l}\text { Drop in TPO-Ab, major effects } \\
\text { with } 200 \mu \mathrm{g} / \text { day }\end{array}$ & (41) \\
\hline & Greece & $6+6$ months & $\begin{array}{c}80 \\
\text { patients } \\
(\mathrm{F})\end{array}$ & $\begin{array}{c}200 \mu \mathrm{g} / \mathrm{day} \\
(\mathrm{SeMe})\end{array}$ & $\begin{array}{l}\text { Drop in TPO-Ab } \\
\text { (-20\% at } 12 \text { months) }\end{array}$ & $(40)$ \\
\hline & Austria & 3 months & $\begin{array}{c}36 \\
\text { patients } \\
(\mathrm{F}) \\
\end{array}$ & $\begin{array}{c}200 \mu \mathrm{g} / \text { day } \\
\text { (Se selenite) }\end{array}$ & No effect on TPO-Ab & (42) \\
\hline & Italy & 12 months & $\begin{array}{c}76 \\
\text { patients } \\
(65 \mathrm{~F} / 11 \\
\mathrm{M})\end{array}$ & $\begin{array}{c}80 \mu \mathrm{g} / \mathrm{day} \\
\text { (Se selenite) }\end{array}$ & Drop in TPO-Ab & (43) \\
\hline & Poland & 6 months & $\begin{array}{c}165 \\
\text { patients }\end{array}$ & $\begin{array}{c}200 \mu \mathrm{g} / \mathrm{day} \\
(\mathrm{SeMe})\end{array}$ & $\begin{array}{l}\text { Reduction in cytokines } \\
\text { production }\end{array}$ & (44) \\
\hline & Greece & 6 months & $\begin{array}{c}86 \\
\text { patients } \\
(53 \mathrm{~F} / 33 \\
\mathrm{M}) \\
\end{array}$ & $\begin{array}{c}200 \mu \mathrm{g} / \mathrm{day} \\
(\mathrm{SeMe})\end{array}$ & $\begin{array}{l}\text { Drop in TPO-Ab } \\
\text { (not significant) }\end{array}$ & $(46)$ \\
\hline PPT & Italy & $\begin{array}{l}\text { Pregnancy and } \\
\text { post partum }\end{array}$ & $\begin{array}{c}232 \\
\text { patients } \\
(\mathrm{F}) \\
\end{array}$ & $\begin{array}{c}200 \mathrm{mcg} / \mathrm{day} \\
\text { (Seme) }\end{array}$ & $\begin{array}{l}\text { Evaluation of the prevalence } \\
\text { of PPTD and hypothyroidism }\end{array}$ & (51) \\
\hline GD & Croatia & 3 months & $\begin{array}{c}57 \\
\text { patients }\end{array}$ & $\begin{array}{l}\text { Vitamin } \mathrm{C} \text { and } \mathrm{E} \text {, } \\
\text { Beta carotene and } \\
\text { Selenium }\end{array}$ & Attainment of Euthyroidism & (58) \\
\hline GO & Italy & $6+6$ months & $\begin{array}{c}159 \\
\text { patients }\end{array}$ & $\begin{array}{c}200 \text { mcg/day } \\
\text { (Selenium) }\end{array}$ & Improvement GO & (62) \\
\hline
\end{tabular}

HT: Hashimoto's thyroiditis; PPT: post-partum thyroiditis; GD: Graves' disease; GO: Graves' ophthalmopathy.

Se reduces anti-thyroid antibodies levels and improves thyroid morphology at ultrasound in patients with Hashimoto's thyroiditis, the administration of Se in addition to methimazole seems to be associated with a faster normalization of hyperthyroidism in patients with Graves' disease, and, finally, Se has been proposed as treatment for mild or moderate Graves' orbithopathy. 
However, the story is not completely clarified yet and additional studies are required to better define doses and modality of Se supplementation.

In addition, other limitations in understanding the role of $\mathrm{Se}$ in thyroid autoimmune diseases are associated with the observation that intrathyroidal Se levels not directly correlate with serum Se concentrations, and, in addition, it should be considered that serum Se assay are expensive and not recommended in routine practice.

Finally, it should be considered that selenium supplementation in subjects with normal selenium levels was associated with an increased risk of type 2 diabetes, and an elevated serum selenium levels were linked to peripheral vascular disease and all-cause mortality in several population studies $(20,21,63)$. Although these findings need to be confirmed, long-term selenium supplementation should not be viewed as harmless and a possibly healthy way to prevent illness, at least in patients with normal/high Se income.

\section{References}

1. Kohrle J, Jakob F, Contempre B, Dumont JE. Selenium, the thyroid, and the endocrine system. Endocr Rev 2005; 26(7):944-984. doi: 10.1210/er.20010034.

2. Rayman MP. The importance of selenium to human health. Lancet 2000; 356(9225):233-241. doi: 10.1016/S0140-6736(00)02490-9.

3. Negro R. Selenium and thyroid autoimmunity. Biologics 2008; 2(2):265-273.

4. Rayman MP. Selenium and human health. Lancet 2012; 379(9822):1256-1268. doi: 10.1016/S01406736(11)61452-9.

5. Schwarz K, Foltz CM. Selenium as an integral part of factor 3 against dietary necrotic liver degeneration. 1951. Nutrition 1999; 15(3):255.

6. Rotruck JT, Pope AL, Ganther HE, Swanson AB, Hafeman DG, Hoekstra WG. Selenium: biochemical role as a component of glutathione peroxidase. Science 1973; 179(4073):588-590.

7. Duntas LH. The role of selenium in thyroid autoimmunity and cancer. Thyroid 2006; 16(5):455-460. doi: 10.1089/thy.2006.16.455.

8. McKenzie RC, Arthur JR, Beckett GJ. Selenium and the regulation of cell signaling, growth, and survival: molecular and mechanistic aspects. Antioxid Redox Signal 2002; 4(2):339-351. doi: 10.1089/15230860 2753666398.

9. Huang Z, Rose AH, Hoffmann PR. The role of selenium in inflammation and immunity: from molecular mechanisms to therapeutic opportunities. Antioxid Redox Signal 2012; 16(7):705-743. doi: 10.1089/ ars.2011.4145.

10. Kohrle J, Gartner R. Selenium and thyroid. Best Pract Res Clin Endocrinol Metab 2009; 23(6):815827. doi: 10.1016/j.beem.2009.08.002.

11. Hawkes WC, Alkan Z. Regulation of redox signaling by selenoproteins. Biol Trace Elem Res 2010; 134(3):235-251. doi: 10.1007/s12011-010-8656-7.
12. Petricca D, Nacamulli D, Mian C, Mantero F, Cavedon E, Girelli ME, Betterle C. Effects of selenium supplementation on the natural course of autoimmune thyroiditis: A short review. J Endocrinol Invest 2012; 35(4):419-424. doi: 10.3275/8302.

13. Burk RF. Clinical effects of selenium deficiency, in Essential and toxic trace elements in human health and disease. AS Prassad, Editor 1988, Liss. A. R.: New York.

14. Selenium. Monograph. Altern Med Rev 2003; 8(1): 63-71.

15. Ashton K, Hooper L, Harvey LJ, Hurst R, Casgrain A. SJ Fairweather-Tait, Methods of assessment of selenium status in humans: a systematic review. Am J Clin Nutr 2009; 89(6):2025S-2039S. doi: 10.3945/ ajcn.2009.27230F.

16. Ferguson LR, Karunasinghe N. Nutrigenetics, nutrigenomics, and selenium. Front Genet 2011; 2: 15 doi: 10.3389/fgene.2011.00015.

17. Reid ME, Stratton MS, Lillico AJ, Fakih M, Natarajan R, Clark LC, Marshall JR. A report of high-dose selenium supplementation: response and toxicities. J Trace Elem Med Biol 2004; 18(1):69-74. doi: 10.1016/j.jtemb.2004.03.004.

18. Navarro-Alarcon M, Cabrera-Vique C. Selenium in food and the human body: a review. Sci Total Environ 2008; 400(1-3): 115-141. doi: 10.1016/j.scitotenv. 2008.06.024.

19. Gore F, Fawell J, Bartram J. Too much or too little? A review of the conundrum of selenium. J Water Health 2010; 8(3):405-416. doi: 10.2166/wh. 2009. 060.

20. Bleys J, Navas-Acien A, Guallar E. Serum selenium and diabetes in U.S. adults. Diabetes Care 2007; 30(4):829-834. doi: 10.2337/dc06-1726.

21. Laclaustra M, Navas-Acien A, Stranges $S$, Ordovas JM, Guallar E. Serum selenium concentrations and diabetes in U.S. adults: National Health and Nutrition Examination Survey (NHANES) 2003-2004. Environ Health Perspect 2009; 117(9): 1409-1413. doi: 10.1289/ehp.0900704.

22. Rayman MP. Food-chain selenium and human health: emphasis on intake. $\mathrm{Br} \mathrm{J}$ Nutr 2008; 100(2):254-268. doi: 10.1017/S0007114508939830.

23. Toulis KA, Anastasilakis AD, Tzellos TG, Goulis DG, Kouvelas D. Selenium supplementation in the treatment of Hashimoto's thyroiditis: a systematic review and a meta-analysis. Thyroid 2010; 20(10):11631173. doi: 10.1089/thy.2009.0351.

24. Dickson RC, Tomlinson RH. Selenium in blood and human tissues. Clin Chim Acta 1967; 16(2): 311321.

25. Glattre E, Mravcova A, Lener J, Vobecky M, Egertova E, Mysliveckova M. Study of distribution and interaction of arsenic and selenium in rat thyroid. Biol Trace Elem Res 1995; 49(2-3):177-186

26. Murillo M, Carrion N, Quintana M, Sanabria G, Rios M, Duarte L, Ablan F. Determination of selenium and iodine in human thyroids. J Trace Elem Med Biol 2005; 19(1):23-27. doi: 10.1016/j.jtemb.2005.07.005

27. Zimmermann MB, Kohrle J. The impact of iron and selenium deficiencies on iodine and thyroid metabo- 
lism: biochemistry and relevance to public health. Thyroid 2002; 12(10): 867-878. doi: 10.1089/105072 502761016494.

28. Howie AF, Walker SW, Akesson B, Arthur JR, Beckett GJ. Thyroidal extracellular glutathione peroxidase: a potential regulator of thyroid-hormone synthesis. Biochem J 1995; 308 ( Pt 3):713-717.

29. Moncayo R, Kroiss A, Oberwinkler M, Karakolcu F, Starzinger M, Kapelari K, Talasz H, Moncayo H. The role of selenium, vitamin $\mathrm{C}$, and zinc in benign thyroid diseases and of selenium in malignant thyroid diseases: Low selenium levels are found in subacute and silent thyroiditis and in papillary and follicular carcinoma. BMC Endocr Disord 2008; 8: 2. doi: 10.1186/1472-6823-8-2.

30. Arthur JR, Beckett GJ. Thyroid function. Br Med Bull 1999; 55(3):658-668.

31. Song Y, Driessens N, Costa M, De Deken X, Detours V, Corvilain B, Maenhaut C, Miot F, Van Sande J, Many MC, Dumont JE. Roles of hydrogen peroxide in thyroid physiology and disease. J Clin Endocrinol Metab 2007; 92(10):3764-3773. doi: 10.1210/jc. 2007-0660.

32. Saad AG, Kumar S, Ron E, Lubin JH, Stanek J, Bove KE, Nikiforov YE. Proliferative activity of human thyroid cells in various age groups and its correlation with the risk of thyroid cancer after radiation exposure. J Clin Endocrinol Metab 2006; 91(7): 26722677. doi: 10.1210/jc.2006-0417.

33. Ekholm R, Bjorkman U. Glutathione peroxidase degrades intracellular hydrogen peroxide and thereby inhibits intracellular protein iodination in thyroid epithelium. Endocrinology 1997; 138(7):2871-2878.

34. Beckett GJ, Arthur JR. Selenium and endocrine systems. J Endocrinol 2005; 184(3): 455-465. doi: 10.1677/joe.1.05971.

35. Stassi G, Di Liberto D, Todaro M, Zeuner A, Ricci-Vitiani L, Stoppacciaro A, Ruco L, Farina F, Zummo G, De Maria R. Control of target cell survival in thyroid autoimmunity by $T$ helper cytokines via regulation of apoptotic proteins. Nat Immunol 2000; 1(6): 483488. doi: $10.1038 / 82725$.

36. Pearce EN, Farwell AP, Braverman LE. Thyroiditis. N Engl J Med 2003; 348(26): 2646-2655. doi: 10.1056/ NEJMra021194.

37. Gartner R, Gasnier BC, Dietrich JW, Krebs B, Angstwurm MW. Selenium supplementation in patients with autoimmune thyroiditis decreases thyroid peroxidase antibodies concentrations. J Clin Endocrinol Metab 2002; 87(4):1687-1691.

38. Gartner R, Gasnier BC. Selenium in the treatment of autoimmune thyroiditis. Biofactors 2003; 19(3-4):165170.

39. Duntas LH, Mantzou E, Koutras DA. Effects of a six month treatment with selenomethionine in patients with autoimmune thyroiditis. Eur J Endocrinol 2003; 148(4): 389-393.

40. Mazokopakis EE, Papadakis JA, Papadomanolaki MG, Batistakis AG, Giannakopoulos TG, Protopapadakis EE, Ganotakis ES. Effects of 12 months treatment with L-selenomethionine on serum antiTPO Levels in Patients with Hashimoto's thyroiditis.
Thyroid 2007; 17(7):609-612. doi: 10.1089/thy. 2007.0040.

41. Turker O, Kumanlioglu K, Karapolat I, Dogan I. Selenium treatment in autoimmune thyroiditis: 9-month follow-up with variable doses. J Endocrinol 2006; 190(1):151-156. doi: 10.1677/joe.1.06661.

42. Karanikas G, Schuetz M, Kontur S, Duan H, Kommata S, Schoen R, Antoni A, Kletter K, Dudczak R, Willheim M. No immunological benefit of selenium in consecutive patients with autoimmune thyroiditis. Thyroid 2008; 18(1): 7-12. doi: 10.1089/thy .2007. 0127.

43. Nacamulli D, Mian C, Petricca D, Lazzarotto F, Barollo S, Pozza D, Masiero S, Faggian D, Plebani M, Girelli ME, Mantero F, Betterle C. Influence of physiological dietary selenium supplementation on the natural course of autoimmune thyroiditis. Clin Endocrinol (Oxf) 2010; 73(4):535-539. doi: 10.1111/j. 1365-2265.2009.03758.x.

44. Krysiak R, Okopien B. The effect of levothyroxine and selenomethionine on lymphocyte and monocyte cytokine release in women with Hashimoto's thyroiditis. $\mathrm{J}$ Clin Endocrinol Metab 2011; 96(7):2206-2215. doi: 10.1210/jc.2010-2986.

45. Balazs C, Kaczur V. Effect of Selenium on HLA-DR Expression of Thyrocytes. Autoimmune Dis 2012; 2012: 374635. doi: 10.1155/2012/374635.

46. Anastasilakis AD, Toulis KA, Nisianakis $P$, Goulis DG, Kampas L, Valeri RM, Oikonomou D, Tzellos TG, Delaroudis S. Selenomethionine treatment in patients with autoimmune thyroiditis: a prospective, quasi-randomised trial. Int J Clin Pract 2012; 66(4): 378-383. doi: 10.1111/j.1742-1241.2011.02879.x.

47. Glinoer D. What happens to the normal thyroid during pregnancy? Thyroid 1999; 9(7): 631-635.

48. Poppe K, Glinoer D. Thyroid autoimmunity and hypothyroidism before and during pregnancy. Hum Reprod Update 2003; 9(2):149-161.

49. Negro R, Mestman JH. Thyroid disease in pregnancy. Best Pract Res Clin Endocrinol Metab 2011; 25(6): 927-943. doi: 10.1016/j.beem.2011.07.010.

50. Prummel MF, Wiersinga WM. Thyroid autoimmunity and miscarriage. Eur J Endocrinol 2004; 150(6): 751755.

51. Negro R, Greco G, Mangieri T, Pezzarossa A, Dazzi $D$, Hassan $H$. The influence of selenium supplementation on postpartum thyroid status in pregnant women with thyroid peroxidase autoantibodies. J Clin Endocrinol Metab 2007; 92(4):1263-1268. doi: 10.1210/jc.2006-1821.

52. Stagnaro-Green A. Approach to the patient with postpartum thyroiditis. J Clin Endocrinol Metab 2012; 97(2): 334-342. doi: 10.1210/jc.2011-2576.

53. Caturegli $P$, Kimura $H$, Rocchi R, Rose NR. Autoimmune thyroid diseases. Curr Opin Rheumatol 2007; 19(1): 44-48. doi: 10.1097/BOR.0b013e3280113d1a.

54. Abalovich M, Llesuy S, Gutierrez S, Repetto M. Peripheral parameters of oxidative stress in Graves' disease: the effects of methimazole and 131 iodine treatments. Clin Endocrinol (Oxf) 2003; 59(3): 321327.

55. Poncin S, Colin IM, Decallonne B, Clinckspooor I, 
Many MC, Denef JF, Gerard AC. N-acetylcysteine and 15 deoxy-\{delta\} 12,14-prostaglandin J2 exert a protective effect against autoimmune thyroid destruction in vivo but not against interleukin-1\{alpha\}/interferon \{gamma\}-induced inhibitory effects in thyrocytes in vitro. Am J Pathol 2010; 177(1):219-228. doi: 10.2353/ajpath.2010.091253.

56. Aihara K, Nishi Y, Hatano S, Kihara M, Yoshimitsu K, Takeichi N, Ito T, Ezaki H, Usui T. Zinc, copper, manganese, and selenium metabolism in thyroid disease. Am J Clin Nutr 1984; 40(1):26-35.

57. Reglinski J, Smith WE, Wilson R, Halls DJ, McKillop $\mathrm{JH}$, Thomson JA. Selenium in Graves' disease. Clin Chim Acta 1992; 211(3):189-190.

58. Vrca VB, Skreb F, Cepelak I, Romic Z, Mayer L. Supplementation with antioxidants in the treatment of Graves' disease; the effect on glutathione peroxidase activity and concentration of selenium. Clin Chim Acta 2004; 341(1-2): 55-63. doi: 10.1016/j.cccn. 2003.10.028.
59. Bahn RS. Graves' ophthalmopathy. N Engl J Med 2010; 362(8):726-738. doi: 10.1056/NEJMra 0905750.

60. Zarkovic M. The role of oxidative stress on the pathogenesis of graves' disease. J Thyroid Res 2012; 2012: 302537. doi: 10.1155/2012/302537.

61. Bouzas EA, Karadimas P, Mastorakos G, Koutras DA Antioxidant agents in the treatment of Graves'ophthalmopathy. Am J Ophthalmol 2000; 129(5):618-622.

62. Marcocci C, Kahaly GJ, Krassas GE, Bartalena L, Prummel M, Stahl M, Altea MA, Nardi M, Pitz S, Boboridis K, Sivelli P, von Arx G, Mourits MP, Baldeschi L, Bencivelli W, Wiersinga W. O European Group on Graves, Selenium and the course of mild Graves' orbitopathy. N Engl J Med 2011; 364(20):1920-1931. doi: 10.1056/NEJMoa1012985.

63. Stranges S, Marshall JR, Natarajan R, Donahue RP, Trevisan M, Combs GF, Cappuccio FP, Ceriello A, Reid ME. Effects of long-term selenium supplementation on the incidence of type 2 diabetes: a randomized trial. Ann Intern Med 2007; 147(4): 217-223. 